\title{
Imaging agents for in vivo molecular profiling of disseminated prostate cancer - targeting EGFR receptors in prostate cancer: Comparison of cellular processing of [ $\left.{ }^{111} \mathrm{In}\right]$-labeled affibody molecule $\mathbf{Z}_{\mathrm{EGFR}: 2377}$ and cetuximab
}

\author{
JENNIE MALMBERG $^{1}$, VLADIMIR TOLMACHEV $^{1,2}$ and ANNA ORLOVA ${ }^{1}$ \\ ${ }^{1}$ Division of Biomedical Radiation Sciences, Rudbeck Laboratory, and ${ }^{2}$ Division of Nuclear Medicine, \\ Uppsala University, S-751 85 Uppsala, Sweden
}

Received October 5, 2010; Accepted December 2, 2010

DOI: $10.3892 /$ ijo.2011.915

\begin{abstract}
Expression of receptor tyrosine-kinase (RTK) EGFR is low in normal prostate, but increases in prostate cancer. This receptor is significantly up-regulated as tumors progress into higher grade, androgen-insensitive and metastatic lesions. The up-regulated receptors could serve as targets for novel selective anti-cancer drugs, e.g. antibodies and tyrosine kinase inhibitors. Radionuclide imaging of RTK can facilitate patient stratification and monitoring of anti-RTK therapy of prostate cancer. The goal of the study was to evaluate binding and cellar processing of radiolabeled EGFRtargeting conjugates by prostate cancer cell lines. Receptor expression of EGFR was studied in three prostate cancer cell lines: DU145 (brain metastasis of PC, hormone insensitive), PC3 (bone metastasis of PC) and LNCaP (lymph node metastasis of PC, androgen and estrogen receptor positive). Uptake and internalization of anti-EGFR mAbs (cetuximab) and affibody molecule $\left(\mathrm{Z}_{2377}\right)$ labeled with indium-111 was investigated. EGFR expression on prostate cancer cell lines was clearly demonstrated. Both labelled conjugates ${ }^{111} \mathrm{In}-\mathrm{Z}_{2377}$ and ${ }^{111}$ In-cetuximab bound to prostate cancer cells in the receptor mediated model. Expression levels were modest but correlate with degree of hormone independence. Internalization of Affibody molecules was relatively slow in all cell lines. Internalization of $\mathrm{mAbs}$ was more rapid. The level of EGFR expression in these cell lines is sufficient for in vivo molecular imaging. Slow internalization indicates possibility of the use of non-residualizing labels for affibody molecules.
\end{abstract}

Correspondence to: Dr Anna Orlova, Division of Biomedical Radiation Sciences, Rudbeck Laboratory, Uppsala University, S75185 Uppsala, Sweden

E-mail: anna.orlova@bms.uu.se

Key words: prostate cancer, EGFR, HER1, imaging, affibody, cetuximab, DU-145, PC3, LNCaP

\section{Introduction}

Prostate cancer (PC) is not one disease, but covers a spectrum of diseases with tumors ranging from localized and slow growing, to rapidly metastasizing and very aggressive. The proliferation of $\mathrm{PC}$ is testosterone-driven and initial androgen ablation therapy typically results in a clinically stable state, lasting 1.5-3 years (1). However, a clonal selection during androgen deprivation therapy promotes development of androgen-independent or hypersensitive (castrate-refractory) cells, which become phenotypically dominating. During development toward androgen independence PC develop alternative cellular signaling pathways promoting growth even in an androgen starved environment. Clonal expansion permit cells with more copies of the androgen receptor gene to flourish and thereby allows for activation despite decreasing androgen levels. Mutations may also lead to a modification of the receptor gene resulting in receptors that respond not only to androgen but to other non-androgenic steroid molecules. Also androgen receptors may be ligand-independently activated by deregulated growth factors or cytokines. Alternatively, PC stem-cells may support the growth of androgen independent cells as the androgen independent cells regress during hormone therapy (2). Median survival of patient with androgen-independent PC is $12-24$ months depending on treatment $(3,4)$.

Hence, detection of changes in phenotype toward androgen independency is highly relevant in patient management to identify the initiation point for a second-line therapy. Moreover, accurate molecular phenotyping might also suggest the most suitable molecular targets for a second-line therapy making the treatment of androgen independent PC more personalized.

One candidate for possible targeted therapy of disseminated PC is epidermal growth factor receptor (EGFR), also known as ErbB1 or HER1. EGFR is a member of a subfamily of four closely related receptor tyrosine kinases: EGFR (ErbB-1), HER2/c-neu (ErbB-2), HER 3 (ErbB-3) and HER 4 (ErbB-4). EGFR has its own natural ligands (among others EGF) and additionally three ligands that it shares with ErbB3 (5). Interaction of EGFR with its ligands triggers the cascade signaling pathway regulating cell proliferation, 
survival, motility and transformation (6). Androgens downregulate EGFR in normal prostate and the loss of such regulation in prostate cancer leads to castrate-refractory tumor growth, invasion, and metastasis (7). Several studies have correlated increased EGFR-expression levels with high grade tumors, advanced stage, high risk of prostate-specific antigen recurrence and association with progression toward androgen-independence (8-10). Other studies indicate that growth factors including EGF can activate androgen receptors in androgen-depleted environment (11).

A confirmed increase in the EGFR expression of androgenindependent PC might open up new possible second-line treatment options by the use of already established and well known EGFR-targeting drugs, such as cetuximab, panitumu$\mathrm{mab}$, and tyrosine kinase inhibitors (TKI). Cetuximab is a chimeric (mouse/human) monoclonal antibody against the epidermal growth factor receptor (EGFR), marketed under the name Erbitux. Cetuximab is already used in clinic to treat patients with epidermal growth factor receptor (EGFR)expressing metastatic colorectal cancer (mCRC), head and neck cancer, non-small cell lung cancer both in combination with chemotherapy, and as a single agent $(12,13)$. The combined Phase I/II trial demonstrated that androgenindependent prostate cancer patients treated with cetuximab in combination with doxorubicin had stabilised disease (14). Another promising candidate for second-line treatment is the new TKI. Among these new target drugs aimed at inhibiting tyrosine-kinase-driven signaling pathways some, such as gefitinib and erlotinib, specifically targets the EGFRsignaling pathway (15). For successful implementation of anti-EGFR therapy to prostate cancer treatment selection of patients that would benefit from this therapy is required.

A diagnostic immunohistochemistry (IHC) assay (EGFR pharmDx) can be used to detect EGFR expression in tumor material. One challenge in IHC is heterogeneity of gene expression in metastases. In principle, biopsy-based methods enable detection of a multitude of genes simultaneously. However, repeated sampling of several metastases is more than questionable in clinics. The use of radionuclide molecular imaging would enable repeated imaging of aberrant expression of different gene products in all metastases simultaneously. Also the use of contemporary combined imaging devices (PET/CT or SPECT/CT) would provide anatomical landmarks for biochemical changes (16).

Among the possible radioimaging agents for EGFR are its natural ligands and anti-EGFR mAbs. The use of natural ligands is limited by their physiological activity that can provoke adverse reactions: nausea, vomiting, diarrhea, hypotension, fever and chills (17). Intact mAbs demonstrated their capacity to image EGFR-expressing tumors (18-20) but the sensitivity of such tracers can be limited by the long biodistribution times, slow tumor penetration, and slow blood clearance of the tracers, which reduces target or non-target contrast. The affibody molecules, a new class of imaging agents combine small size of natural ligands, absence of physiological action, and high affinity to target and can be used for radioimmuno-diagnostic.

Affibody molecules are proteins composed of a threehelix bundle based on the scaffold of one of the IgG-binding domains of protein A. By randomizing 13 of the amino acid residues in the helices 1 and 2, combinatorial affibody libraries have been created for selection of binders for a multitude of proteins (21). Their design gives them an outstanding affinity for a specific biomarker and allows them to be used as carriers of imaging/therapeutic radionuclides or toxins. This makes affibody molecules promising for imaging to both localized and metastatic types of tumors, hence endorsing a more personalized approach to treatment. In addition, affibody molecules have an advantage over the conventional monoclonal antibodies as they mimic their function, but lack the non-target interactions of antibodies.

Bio-distribution properties of affibody molecules surpass those of antibodies or their fragments. In contrast to the $150 \mathrm{kDa}$ weight of an antibody, the molecular weight of affibody is only $7 \mathrm{kDa}$, which provides rapid extravasation and penetration in extracellular space of tumors. The affibody molecule $\mathrm{Z}_{\mathrm{EGFR}: 2377}$ has previously demonstrated superb targeting with high specificity to EGFR-expressing A431 (squamous carcinoma) xenografts in murine models confirmed by $\gamma$-camera imaging (22) making $\mathrm{Z}_{\mathrm{EGFR}: 2377}$ a possible candidate also for imaging of EGFR-expression in PC metastases.

The aims of the study was to establish the level of HER1/ EGFR expression in a range of PC cell-lines in order to use them as models in further studies, and to evaluate the binding and cellular processing of $\left[{ }^{111} \mathrm{In}\right]$-labeled cetuximab and $\mathrm{Z}_{\mathrm{EGFR}: 2377}$ to these cell lines.

\section{Materials and methods}

Cell lines. Three different PC cell lines were evaluated for EGFR-receptor expression and had their receptor amount quantified. The cell lines, all originating from PC metastases, were DU145 (brain metastasis of PC, hormone insensitive), PC3 (bone metastasis of PC) and LNCaP (lymph node metastasis of PC, androgen and estrogen receptor positive). All cell lines were provided by the American Type Culture Collection.

The cells were cultivated in complete RPMI-media, supplemented with $10 \%$ fetal bovine serum (FBS), 2 mM Lglutamate, $100 \mathrm{IU} / \mathrm{ml}$ penicillin and $100 \mu \mathrm{g} / \mathrm{ml}$ of streptomycin. For the LNCap cells media were also supplemented with Na-pyruvate and HEPES. All reagents including media and Trypsin-EDTA were from Biochrom KG, Berlin, Germany. All bottles and petri-dishes for cell cultivation were from Nunclon surface, Roskilde, Denmark. Cultivation of cells took place in a humidified incubator with $5 \% \mathrm{CO}_{2}$ at $37^{\circ} \mathrm{C}$, if not stated otherwise.

Materials. EGFR-binding $\mathrm{Z}_{\mathrm{EGFR}: 2377}$ affibody molecule with site-specifically coupled maleimido derivative of DOTA was provided by Affibody AB (Bromma, Sweden). Development and characterization of DOTA-Z $Z_{\text {EGFR:2377 has }}$ been described earlier (15). Anti-EGFR chimerical monoclonal antibody cetuximab (Erbitux ${ }^{\circledR}$ ) was from Merck AB (Stockholm, Sweden). [(R)-2-Amino-3-(4-isothiocyanatophenyl)propyl]-trans-(S,S)-cyclohexane-1,2-diaminepentaacetic acid (CHX-A"DTPA) was purchased from Macrocyclics (Dallas, TX, USA).

Buffers, such as $0.1 \mathrm{M}$ phosphate buffered saline (PBS), $\mathrm{pH}$ 7.5, 0.007 $\mathrm{M}$ sodium borate, $\mathrm{pH}$ 9.3, $4 \mathrm{M}$ urea solution in 
a $0.1 \mathrm{M}$ glycine buffer, $\mathrm{pH} 2.5$, and $0.2 \mathrm{M}$ ammonium acetate, $\mathrm{pH} 5.5$, were prepared using common methods and chemicals supplied by Merck (Darmstadt, Germany). High-quality MilliQ ${ }^{\odot}$ water (resistance higher than $18 \mathrm{M} \Omega / \mathrm{cm}$ ) was used for preparing solutions. PD-10 and NAP-5 columns were both from GE Healthcare (Uppsala, Sweden). Buffers which were used for conjugation and labeling were purified from metal contaminations using Chelex 100 resin from Bio-Rad Laboratories (Richmond, CA, USA). [ $\left.{ }^{111} \mathrm{In}\right]$-indium chloride solution was purchased from Coviden (Hazelwood, USA).

Instrumentation. The radioactivity was measured using an automated $\gamma$-counter with 3-inch $\mathrm{NaI}(\mathrm{Tl})$ detector (1480 Wizard, Wallac Oy, Turku, Finland). Indium-111 was measured with the use of both photo peaks and summation peak (energy setting from 140 to $507 \mathrm{keV}$ ).

The distribution of radioactivity along the strips was measured on a Cyclone ${ }^{\mathrm{TM}}$ Storage Phosphor System (further referred to as Phosphor Imager) and analyzed using the OptiQuant $^{\mathrm{TM}}$ image analysis software (both from PerkinElmer). Cells were counted using an electronic cell counter (Beckman Coulter).

Labeling chemistry. For labeling, DOTA-Z $\mathrm{EGFR}_{2377}$ was reconstituted in $0.2 \mathrm{M}$ ammonium acetate buffer to a concentration of $1 \mathrm{mg} / \mathrm{ml}$. For a typical labeling, $30 \mu 1$ of DOTA-Z $\mathrm{EGFR}: 2377$ solution was mixed with $50 \mu 10.2 \mathrm{M}$ ammonium acetate buffer and 30-70 MBq [ $\left.{ }^{111} \mathrm{In}\right]$-indium chloride (80-160 $\mu 1$ solution in $0.05 \mathrm{M} \mathrm{HCl})$. The reaction mixture was incubated at $60^{\circ} \mathrm{C}$ for $30 \mathrm{~min}$ and the radiochemical purity was evaluated using Tec-Control Chromatography 150-771 strips (Biodex Medical Systems, New York, US) eluted with $0.2 \mathrm{M}$ citric acid.

Cetuximab was labeled with [ $\left.{ }^{111} \mathrm{In}\right]$-indium chloride solution using CHX-A"DTPA chelator. The coupling ( 4 chelators per antibody) was performed in accordance with the method described earlier (23). Briefly, cetuximab was purified from glycine using PD-10 column, equilibrated and eluted with MilliQ water, and then freeze-dried. For coupling, $1.4 \mathrm{mg}$ antibody was re-constituted in $200 \mu 10.07 \mathrm{M}$ sodium borate and a freshly prepared solution of CHX-A"DTPA $(27 \mu 1,1 \mathrm{mg} / \mathrm{ml}$ in $0.07 \mathrm{M}$ sodium borate) was added. The mixture was incubated at $37^{\circ} \mathrm{C}$ for $4 \mathrm{~h}$, then CHX-A"DTPA-cetuximab was purified from unreacted chelator using NAP-5 column equilibrated and eluted with $0.2 \mathrm{M}$ ammonium acetate. The CHX-A"DTPA-cetuximab was divided in aliquots, $100 \mu \mathrm{g}$ in $64 \mu 10.2 \mathrm{M}$ ammonium acetate and stored at $-20^{\circ} \mathrm{C}$.

For a typical labeling, an aliquot of CHX-A"DTPAcetuximab was mixed with $12 \mu 1(10 \mathrm{MBq})\left[{ }^{111} \mathrm{In}\right]$-indium chloride solution. The mixture was incubated for $60 \mathrm{~min}$ at ambient temperature and then analyzed using Tec-Control Chromatography 150-771 strips.

In vitro binding specificity test. Pre-cultivated cells from cell lines DU-145, PC3 or LNCap were incubated for $1 \mathrm{~h}$ with $1 \mathrm{nM}$ solution of [ $\left.{ }^{111} \mathrm{In}\right]-\mathrm{Z}_{\mathrm{EGFR}: 2377}$ or $\left[{ }^{111} \mathrm{In}\right] \mathrm{CHX}-\mathrm{A}$ "-DTPAcetuximab in medium. Along with these one set of dishes was treated in the same way, but with a blocking amount of non-labeled $\mathrm{Z}_{\mathrm{EGFR}: 2377}$ or cetuximab added before the radioactive solution. The experiments were done in triplicates.
Following incubation media were collected and the cell cultures were treated with $0.5 \mathrm{ml}$ trypsine-EDTA for 10 min at $37^{\circ} \mathrm{C}$. Media $(0.5 \mathrm{ml})$ was added to each dish and the cells were re-suspended. Cell-suspension was also collected.

Media and cell samples were measured for radioactivity content and cell associated radioactivity was calculated as (Cell associated radioactivity, CPM) x100\%/[(Cell associated radioactivity, CPM)+(Radioactivity in media, CPM)]. Significance of blocking was analyzed by t-test.

Quantification of EGFR expression in PC cell lines. To calculate the number of receptors pre-cultivated cells from cell lines DU-145, PC3 or LNCap were incubated for $4 \mathrm{~h}$ at $4^{\circ} \mathrm{C}$ with [ $\left.{ }^{111} \mathrm{In}\right] \mathrm{CHX}-\mathrm{A}^{1}$-DTPA-cetuximab in concentrations ranging from 0.2 to $33 \mathrm{nM}$ in complete media. For each data point four dishes were used including 1 pre-saturated with unlabeled cetuximab $(3 \mu \mathrm{M})$ in complete media. For each data point one standard sample was also taken for further calculations of real concentrations in data points. After incubation medium was aspired and the cells were washed once with cold serum-free medium. The cells were treated with trypsin for 10-15 min and then the cells in each dish were resuspended after addition of $1 \mathrm{ml}$ of medium. Cell suspension $(0.5 \mathrm{ml})$ was used for cell counting and $1 \mathrm{ml}$ for radioactivity measurements.

The cellular binding and processing of radiolabeled conjugates. Pre-cultivated cells from cell lines DU-145, PC3 or LNCap were incubated with $1 \mathrm{nM}$ solution of [ $\left.{ }^{111} \mathrm{In}\right]-\mathrm{Z}_{\mathrm{EGFR}: 2377}$ or [ $\left.{ }^{111} \mathrm{In}\right] \mathrm{CHX}-\mathrm{A}$ "-DTPA-cetuximab, in complete media, at $37^{\circ} \mathrm{C}$. At designed times of incubation $(0.5,1,2,3,4,8$ and $24 \mathrm{~h}$ ) one group of 3 dishes was analyzed for cell-associated radioactivity.

The membrane bound radioactivity was determined by method described earlier (24). After washing cells were treated with $0.5 \mathrm{ml} 4 \mathrm{M}$ urea solution in a $0.1 \mathrm{M}$ glycine buffer with pH 2.5, for $5 \mathrm{~min}$ on ice. The acid fraction was collected and the cells were washed in an additional $0.5 \mathrm{ml}$ acid solution, then collected. Following this the cells were lysed and collected for measurement of internalized radioactivity. For lysis, $0.5 \mathrm{ml}$ of $1 \mathrm{M}$ sodium hydroxide solution was added and the cells were incubated at $37^{\circ} \mathrm{C}$ for at least $0.5 \mathrm{~h}$. The basic solution was collected. Dishes were washed with an additional $0.5 \mathrm{ml}$ basic solution and the basic fractions pooled. The radioactivity content of the samples was measured by an automated $\gamma$-counter.

\section{Results}

Conjugation and labeling chemistry. [ $\left.{ }^{111} \mathrm{In}\right]$-labeling of DOTA$\mathrm{Z}_{\mathrm{EGFR}: 2377}$ provided a yield of over $95 \%$ and a specific activity of 16.8 MBq/nmol. Labeling of CHX-A"DTPA-cetuximab was also successful and provided a yield of $99 \%$ and a specific activity of $15 \mathrm{MBq} / \mathrm{nmol}$.

A consistent labeling yield of over $95 \%$ allowed for the labeled proteins to be used without purification and they were subsequently diluted with PBS for further experiments.

In vitro binding specificity test. The results of the in vitro specificity test for [ $\left.{ }^{111} \mathrm{In}\right]-\mathrm{DOTA}-\mathrm{Z}_{\mathrm{EGFR}: 2377}$ and [ $\left.{ }^{111} \mathrm{In}\right]-\mathrm{CHX}$ - 
$Z_{2377}$

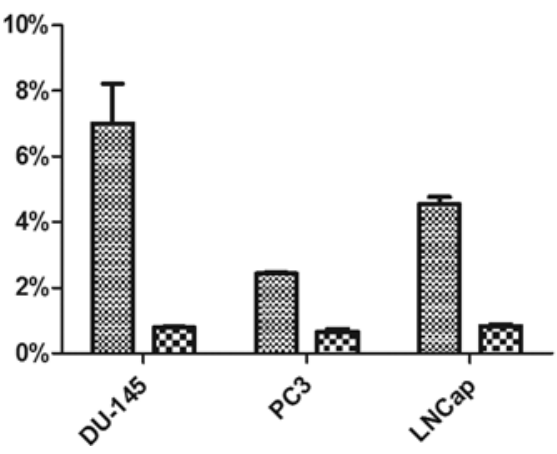

Cetuximab

Non-blocked Blocked

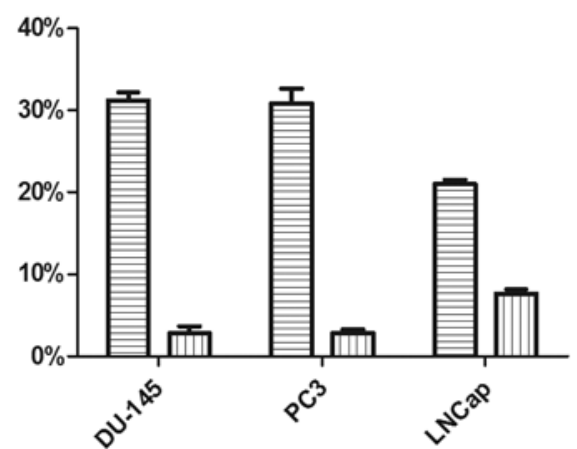

Figure 1. Specificity of radiolabeled tracers ([111 In]CHX-A"DTPA-cetuximab and $\left[{ }^{111} \mathrm{In}\right]-\mathrm{Z}_{\mathrm{EGFR}: 2377}$ ) binding to prostate cancer cells in vitro. For each of the tracers, one group of cell culture dishes was pre-treated with saturating amounts of non-labeled counterpart before incubation with the [ ${ }^{111}$ In]-labelled tracer. Cell-associated radioactivity was calculated as $\%$ of total added radioactivity. Reduction of cell-bound radioactivity due to receptor saturation confirms specific binding. Data are presented as an average of three samples with standard deviations, error bars might be not seen because they are smaller than point symbols.

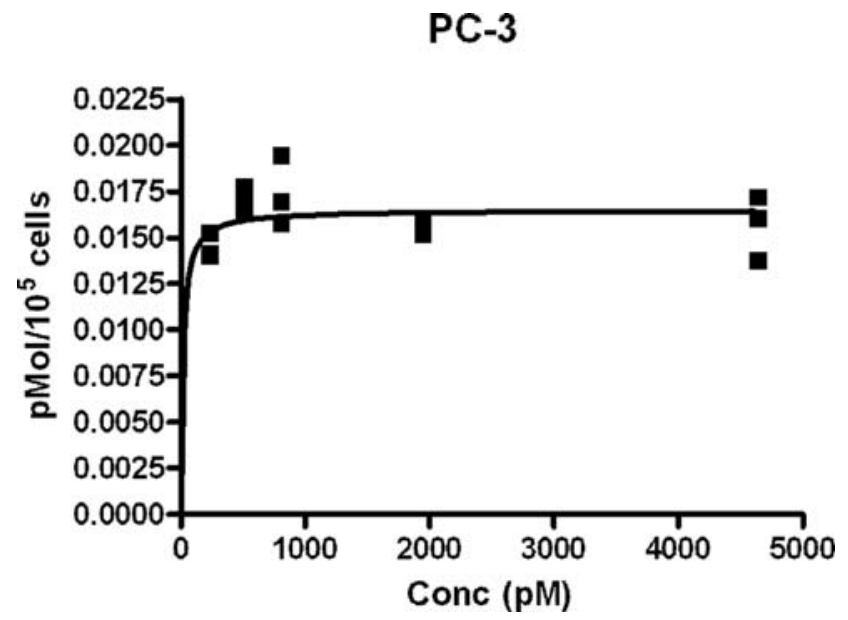

Figure 2. Non-linear regression analysis of data from a typical binding saturation experiment. Increasing concentrations of [ $\left.{ }^{111} \mathrm{In}\right] \mathrm{CHX}-\mathrm{A}$ "DTPAcetuximab (X-axis) were added to dishes with PC3 cells. The cells were incubated with [111 In]CHX-A"DTPA-cetuximab at $4^{\circ} \mathrm{C}$ to prevent internalization. After $4 \mathrm{~h}$ long incubation, the cells were then harvested, and bound radioactivity (y-axis) was measured.

A"DTPA-cetuximab are presented in Fig. 1. With both compounds, the binding to PC cells was highly specific and the results clearly confirm the presence of EGFR in all the cell lines tested.

For [ $\left.{ }^{111} \mathrm{In}\right]$-labeled $\mathrm{Z}_{\mathrm{EGFR}: 2377}$ pre-saturation of the EGFreceptors with non labeled $\mathrm{Z}_{\mathrm{EGFR}: 2377}$ significantly decreased the binding of the conjugate from $7.00 \pm 1.22 \%$ to $0.79 \pm 0.02 \%$ for $\mathrm{LNCaP}$, from $2.41 \pm 0.06 \%$ to $0.63 \pm 0.10 \%$ for $\mathrm{PC} 3$, and from $4.54 \pm 0.21 \%$ to $0.83 \pm 0.05 \%$ for DU145 PC cell lines.

Pre-saturation of EGFR with non-labeled cetuximab decreased the binding of [ $\left.{ }^{111} \mathrm{In}\right]-\mathrm{CHX}-\mathrm{A}$ "DTPA-cetuximab from $31.19 \pm 0.95 \%$ to $2.82 \pm 0.80 \%$ for $\mathrm{LNCaP}$, from $30.89 \pm 1.72 \%$ to $2.87 \pm 0.34 \%$ for PC 3 , and from $21.00 \pm 0.53 \%$ to $7.60 \pm 0.55 \%$ for DU145 PC cell lines.

Quantification of EGFR expression in PC cell lines. EGFR expression level was quantified using saturation experiments
Table I. Table displaying the expression of EGFR-receptors by prostate cell lines in vitro.

\begin{tabular}{lc} 
Cell line & Receptors per cell \\
\hline LNCap & $43,000 \pm 11,000$ \\
PC3 & $99,000 \pm 3,000$ \\
DU-145 & $207,000 \pm 13,000$ \\
\hline
\end{tabular}

The data are obtained by non-linear regression analysis of saturation experiments with [ $\left.{ }^{111} \mathrm{In}\right]-\mathrm{CHX}-\mathrm{A}$ "-DTPA-cetuximab. The data are presented as an averaged number of receptor per cell \pm standard deviation.

with [ $\left.{ }^{111} \mathrm{In}\right]-\mathrm{CHX}-\mathrm{A}$ "DTPA-cetuximab. The results of a typical saturation experiment are presented in Fig. 2.

All cell lines demonstrate modest but detectable expression levels. Quantitative data concerning EGFR expression are presented in Table I.

The cellular binding and processing of radiolabeled conjugates. Data on binding and cellular processing of [ $\left.{ }^{111} \mathrm{In}\right]-$ DOTA-Z $Z_{\text {EGFR:2377 }}$ and [ $\left.{ }^{111} \mathrm{In}\right]-\mathrm{CHX}-\mathrm{A}$ "DTPA-cetuximab are presented in Fig. 3. The two conjugates display a rather different binding and uptake-pattern. For affibody molecules, in both PC3 and LNCap, an initial rapid binding was followed by slow but continuous increase in uptake during $24 \mathrm{~h}$ of incubation. With DU-145, on the other hand, a fast initial binding of [ $\left.{ }^{111} \mathrm{In}\right]-\mathrm{DOTA}-\mathrm{Z}_{\mathrm{EGFR}: 2377}$ was followed by a plateau after $8 \mathrm{~h}$ of incubation. Cetuximab displayed, in all cases, a much faster initial binding and a continuous increase during all $24 \mathrm{~h}$ of incubation. Such pattern may be due to continuous cell proliferation and absence of EGFR down-regulation.

Internalization of both conjugates was continuously growing during whole incubation. The internalization rate, for the affibody molecule, was slow but steadily increasing. With cetuximab internalization curves followed the rater steep binding curves, continuously increasing throughout the 


\section{${ }^{111}$ In-cetuximab} ${ }^{111} \ln -Z_{2377}$
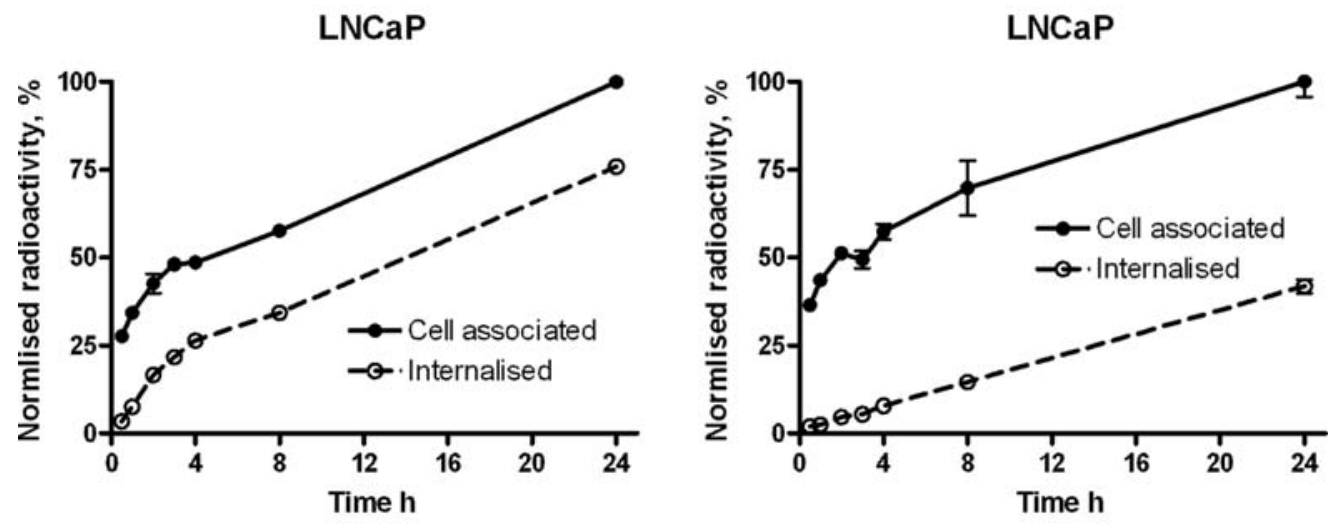

PC3

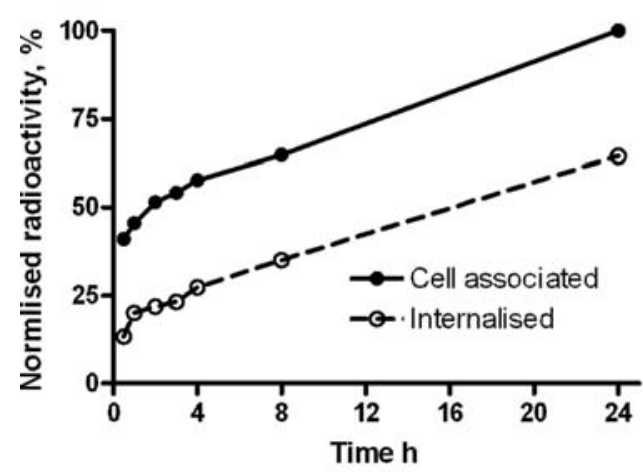

PC3

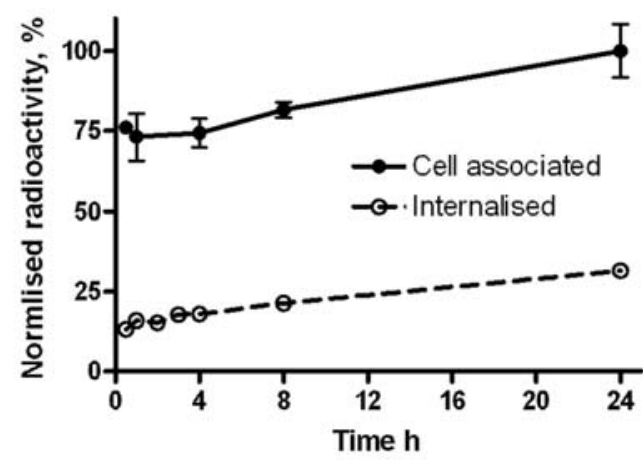

DU145

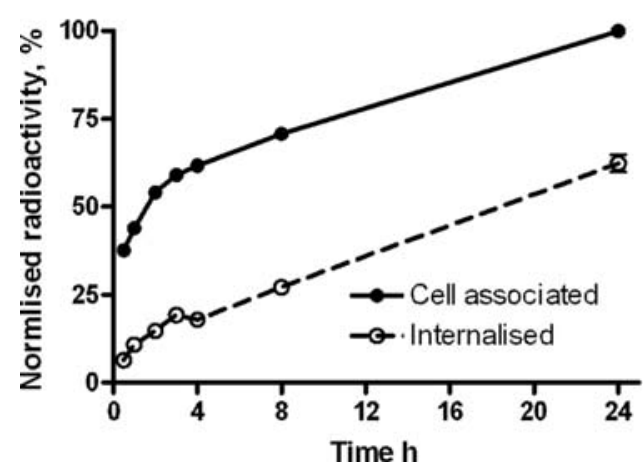

DU145

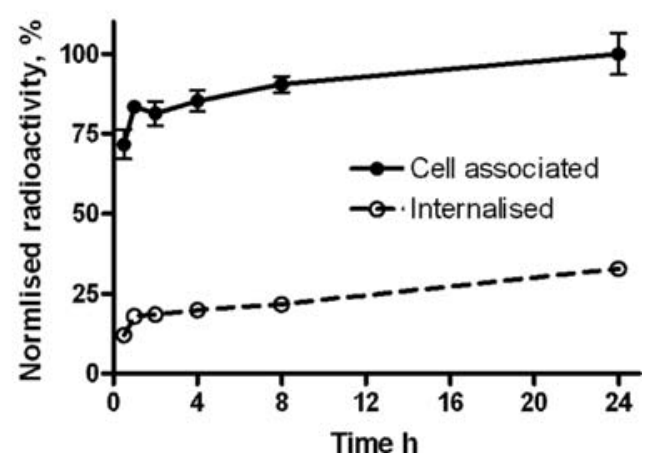

Figure 3. Binding and cellular processing of $\left[{ }^{111} \mathrm{In}\right]-\mathrm{CHX}-\mathrm{A}$ "DTPA-cetuximab and $\left[{ }^{111} \mathrm{In}\right]-\mathrm{Z}_{\mathrm{EGFR}: 2377}$ by prostate cancer cells at continuous incubation at $37^{\circ} \mathrm{C}$. Data presented as an average of three samples with standard deviations, error bars might be not seen because they are smaller than point symbols.

$24 \mathrm{~h}$ of incubation. In the case of $\left[{ }^{111} \mathrm{In}\right]-\mathrm{CHX}-\mathrm{A}$ "DTPAcetuximab more than $60 \%$ of delivered radioactivity was internalized after $24 \mathrm{~h}$, while internalization of radioactivity delivered by [ [111In]-DOTA-Z $Z_{\text {EGFR:2377 }}$ only reached about $30 \%$.

\section{Discussion}

PC is notoriously difficult to diagnose and current methods of diagnosis and staging are in many cases inadequate. For a newly diagnosed patient, information regarding the location of the cancer is critical in the decision between local or systemic treatment. For patients with occult recurrent disease it is equally necessary to know not only whether or not recurrence is local or disease is metastasized, but also what type of therapy can be appropriate. Initial treatment of metastasized prostate cancer usually utilizes hormonemediated therapies that generally results in rapid response. Unfortunately, these androgen deprivation therapies are not curative and patients will ultimately develop androgenindependent disease with further progression. The progress 
on new treatments for castrate-refractory PC has been slow and second-line treatment for patients with recurring PC is limited. Several clinical trials have been performed, with inadequate success (24). Molecular changes in PC cells that are driving forth for castrate-refractory PC, such as overexpression of growth factor receptors, can be the new promising target for future therapy approaches (25).

A correlation between an increase in EGFR-expression and poor prognosis is confirmed in several types of cancer, including PC $(26,27)$. As overexpression of EGFR seems to be a factor in the progression of $\mathrm{PC}$ and its development toward androgen-independence (28) EGFR is of outmost interest when targeting disseminated PC.

Currently the main method for determination of EGFRexpression is IHC. However, IHC is a technique that requires both high sample quality and skilled staff, to grant reliable and comparable results/data (29). Important to point out is also that $\mathrm{ICH}$ requires biopsies and as bone metastasis is the most common form of metastasis in disseminated PC this complicates the situation. In order to make an informed decision regarding treatment and to personalize the treatment, the data regarding the phenotype of the tumor and the spread of the disease needs to be as complete as possible and this is where radionuclide imaging may be useful.

In clinic cetuximab is proven effective and is commonly used in the treatment of high EGFR-expressing tumors. A recent trial by Slovin et al (14) used cetuximab for combined treatment of disseminated castrate-resistant PC. Although there was no apparent regression of the disease among the participants of the trial median survival were longer than in historical control groups. That study is an early experience with cetuximab in PC and was suboptimally designed both in cetuximab dosage and choice of doxorubicin with its limited efficacy, but demonstrated promising results. To be able to select PC patients for the new anti-EGFR therapy the imaging of EGFR expression in PC lesions is necessary.

This study was a first step in characterization of a range of PC cell-lines in order to establish new research models for the comparison of potential imaging probes. Expression of EGFR was clearly demonstrated in all three prostate-cancer cell-lines (Table I) and correlates with different degree of androgen independence (DU145, brain metastasis of PC, hormone insensitive $>\mathrm{PC} 3$, bone metastasis of $\mathrm{PC}$, moderate hormone sensitive $>\mathrm{LNCaP}$, lymph node metastasis of PC, androgen and estrogen receptor positive). Together these cell lines constitute a panel that can be used to develop antiEGFR imaging agents, therapy modalities, and measure treatment induced changes in the EGFR expression-levels. Previous experiments (30-32) have shown that even cells with moderate expression levels may be utilized for in vivo experiment, indicating a possibility to visualize tumors with proportionally relatively minor aberrations in their expression profile. Cell lines with different EGFR expression can be also useful in determining optimal specific radioactivity of imaging agent for better contrast $(21,33)$.

Several aspects are important for imaging agent, such as high specificity and selectivity to the target, robustness in labeling conditions and maintenance of binding capacity after necessary modifications, rate of blood clearance, excretion pathways, and many others. Also important for development of a tracer is internalization rate of the conjugate after binding to the target. Internalization is followed by transfer to the lysosomal compartment, where targeting proteins undergo proteolytic degradation. Charged radiocatabolites of radiometal labels stay trapped intracellularly, while lipophilic catabolites of radiohalogens leak from cells decreasing tumor-associated radioactivity (34). For tracers used in imaging it is noteworthy that larger targeting agents, such as antibodies, have a long circulation time in blood. The longer circulation contributes higher background radiation and cause a reduction in imaging contrast. Smaller tracers with their shorter circulation time give less background radiation and therefore provide better sensitivity (35). The shorter circulation time may also have clinical implications as reduction in hospital-time is of practical interest for patients and of economical interest for caregivers.

Both tested In-labeled conjugates demonstrated specific receptor mediated binding to all three studied PC cell lines (Fig. 1) confirming that conjugates preserved binding capacity to EGFR under labeling procedures. Internalization of anti-EGFR conjugates was studied in details on all three cell lines and the results are presented in Fig. 3. In line with previous studies $(21,36,30,31)$ on breast and ovarian carcinoma cell lines internalization of affibody molecules is slow but it could not be excluded a priori that internalization of affibody molecules would proceed at different rate in PC cells. As can be expected, a larger number of receptors in the cell lines reflects in the overall uptake giving a higher uptake to the cell lines with more receptors.

The faster uptake and internalization of cetuximab, put higher emphasis on the properties of the nuclide used for radiolabeling. A residualizing label is necessary, in this case, to prevent leakage of radiocatabolites that may disrupt imaging and deteriorate the quality of the images. With affibody molecules on the other hand the properties of the nuclide is of less importance and the main issue is rather of affinity. This since the affibody molecules have a much slower internalization rate, meaning that disassociation of labeled tracer would be a potentially greater issue than leakage of radiocatabolites.

Affibody molecules have on several occasions demonstrated promise as tracers for molecular imaging (37-39) and the design of the affibody molecule makes it highly versatile and adaptable. Selecting affibody molecules, with binding sites that target epitopes slightly different from the ones in drugs used for treatment, is feasible. This presents the possibility to utilize affibody molecules as tracers to continuously track result of treatment and further personalize treatment regimens.

In conclusion, the level of EGFR expression in these cell lines is sufficient for in vivo molecular imaging. Slow internalization indicates the possibility of using non-residualizing labels for affibody molecules.

\section{References}

1. Pienta KJ and Bradley D: Mechanisms underlying the development of androgen-independent PC. Clin Cancer Res 12: 1665-1671, 2006.

2. Pienta KJ and Smith DC: Advances in PC chemotherapy: A new era begins. CA Cancer J Clin 55: 300-318, 2005. 
3. Tannock IF, de Wit R, Berry WR, et al: For the TAX 327 investigators: Docetaxel plus prednisone or mitoxantrone plus prednisone for advanced PC. N Engl J Med 351: 1502-1512, 2004.

4. Petrylak DP, Tangen CM, Hussain MH, et al: Docetaxel and estramustine compared with mitoxantrone and prednisone for advanced refractory PC. N Engl J Med 351: 1513-1520, 2004.

5. Marmor MD, Skaria KB and Yarden Y: Signal transduction and oncogenesis by ErbB/HER receptors. Int J Radiat Oncol Biol Phys 58: 903-913, 2004

6. Oda K, Matsuoka Y, Funahashi A and Kitano H: A comprehensive pathway map of epidermal growth factor receptor signalling. Mol Syst Biol 1: 2005.0010, 2005.

7. Traish AM and Morgentaler A: Epidermal growth factor receptor expression escapes androgen regulation in prostate cancer: a potential molecular switch for tumour growth. Br J Cancer 101: 1949-1956, 2009.

8. Hernes E, Fosså SD, Berner AA, Otnes B and Nesland JM: Expression of the epidermal growth factor receptor family in prostate carcinoma before and during androgen-independence. Br J Cancer 90: 449-454, 2004

9. Schlomm T, Kirstein P, Iwers L, et al: A. Clinical significance of epidermal growth factor receptor protein overexpression and gene copy number gains in PC. Clin Cancer Res 13: 65-79, 2007.

10. Shaw G and Prowse DM: Inhibition of androgen-independent PC cell growth is enhanced by combination therapy targeting Hedgehog and ErbB signaling. Cancer Cell Int 8: 3, 2008.

11. Culig Z, Hobisch A, Cronauer MV, et al: Androgen receptor activation in prostatic tumor cell lines by insulin-like growth factor-I, keratinocyte growth factor, and epidermal growth factor. Cancer Res 54: 5474-5478, 1994.

12. Schrag D: The price tag on progress - chemotherapy for colorectal cancer. N Engl J Med 351: 317-319, 2004.

13. Rocha-Lima CM, Soares HP, Raez LE and Singal R: EGFR targeting of solid tumors. Cancer Control 14: 295-304, 2007.

14. Slovin SF, Kelly WK, Wilton A, Kattan M, Myskowski P, Mendelsohn J and Scher HI: Anti-epidermal growth factor receptor monoclonal antibody cetuximab plus Doxorubicin in the treatment of metastatic castration-resistant PC. Clin Genitourin Cancer 7: E77-E82, 2009.

15. Tolmachev V, Stone-Elander S and Orlova A: Radiolabelled receptor-tyrosine-kinase targeting drugs for patient stratification and monitoring of therapy response: prospects and pitfalls. Lancet Oncol 11: 992-1000, 2010

16. Pantaleo MA, Nannini M, Maleddu A, et al: Experimental results and related clinical implications of PET detection of epidermal growth factor receptor (EGFr) in cancer. Ann Oncol 20: 213-226, 2009.

17. Cuartero-Plaza A, Martínez-Miralles E, Rosell R, Vadell-Nadal C, Farré M and Real FX: Radiolocalization of squamous lung carcinoma with 131I-labeled epidermal growth factor. Clin Cancer Res 2: 13-20, 1996.

18. Nayak TK, Regino CA, Wong KJ, et al: PET imaging of HER1expressing xenografts in mice with 86Y-CHX-A"-DTPAcetuximab. Eur J Nucl Med Mol Imaging 37: 1368-1376, 2010.

19. Nayak TK, Garmestani K, Baidoo KE, Milenic DE and Brechbiel MW: Preparation, biological evaluation, and pharmacokinetics of the human anti-HER1 monoclonal antibody panitumumab labeled with $86 \mathrm{Y}$ for quantitative PET of carcinoma. J Nucl Med 51: 942-950, 2010.

20. Milenic DE, Wong KJ, Baidoo KE, Ray GL, Garmestani K, Williams $M$ and Brechbiel MW: Cetuximab: preclinical evaluation of a monoclonal antibody targeting EGFR for radioimmunodiagnostic and radioimmunotherapeutic applications. Cancer Biother Radiopharm 23: 619-631, 2008.

21. Nygren PA: Alternative binding proteins: affibody binding proteins developed from a small three-helix bundle scaffold FEBS J 275: 2668-2676, 2008
22. Tolmachev V, Rosik D, Wållberg $\mathrm{H}$, et al: Imaging of EGFR expression in murine xenografts using site-specifically labelled anti-EGFR ${ }^{111}$ In-DOTA-ZEGFR:2377 Affibody molecule: aspect of the injected tracer amount. Eur J Nucl Med Mol Imaging 37: 613-622, 2010.

23. Almqvist Y, Steffen AC, Tolmachev V, Divgi CR and Sundin A: In vitro and in vivo characterization of 177Lu-huA33: a radioimmunoconjugate against colorectal cancer. Nucl Med Biol 33: 991-998, 2006.

24. Garmey EG, Sartor O, Halabi S and Vogelzang NJ: Second-line chemotherapy for advanced hormone-refractory PC. Clin Adv Hematol Oncol 6: 118-132, 2008

25. Jakobovic A: Monoclonal antibody therapy for prostate cancer. Handb Exp Pharmacol 181: 237-256, 2008.

26. Shah T, Hochhauser D, Frow R, Quaglia A, Dhillon AP and Caplin ME: Epidermal growth factor receptor expression and activation in neuroendocrine tumours. J Neuroendocrinol 18 : 355-360, 2006.

27. Shah RB, Ghosh D and Elder JT: Epidermal growth factor receptor (ErbB1) expression in PC progression: correlation with androgen independence. Prostate 66: 1437-1444, 2006.

28. Hernes E, Fosså SD, Berner A, Otnes B and Nesland JM: Expression of the epidermal growth factor receptor family in prostate carcinoma before and during androgen-independence. Br J Cancer 90: 449-454, 2004

29. Dei Tos AP and Ellis I: Assessing epidermal growth factor receptor expression in tumours: what is the value of current test methods? Eur J Cancer 41: 1383-1392, 2005.

30. Ahlgren S, Wållberg H, Tran TA, et al: Targeting of HER2expressing tumors with a site-specifically $99 \mathrm{mTc}$-labeled recombinant affibody molecule, ZHER2:2395, with C-terminally engineered cysteine. J Nucl Med 50: 781-789, 2009.

31. Ahlgren S, Orlova A, Wållberg H, et al: Targeting of HER2expressing tumors using ${ }^{111} \mathrm{In}-\mathrm{ABY}-025$, a second generation Affibody molecule with a fundamentally re-engineered scaffold. J Nucl Med 51: 1131-1138, Epub Jun 16, 2010.

32. Tran TA, Rosik D, Abrahmsén L, et al: Design, synthesis and biological evaluation of a multifunctional HER2-specific Affibody molecule for molecular imaging. Eur J Nucl Med Mol Imaging 36: 1864-1873, 2009

33. Tolmachev V, Wållberg H, Sandström M, Hansson M, Wennborg A and Orlova A: Optimal specific radioactivity of anti-HER2 Affibody molecules enables discrimination between xenografts with high and low HER2 expression levels. Eur J Nucl Med Mol Imaging: Nov 15, 2010 (Epub ahead of print).

34. Khaw BA, Cooney J, Edington T and Strauss HW: Differences in experimental tumor localization of dual-labeled monoclonal antibody. J Nucl Med 27: 1239-1239, 1986.

35. Tolmachev V, Xu H, Wållberg H, et al: Evaluation of a maleimido derivative of CHX-A" DTPA for site-specific labeling of Affibody molecules. Bioconjug Chem 19: 1579-1587, 2008.

36. Wållberg $\mathrm{H}$ and Orlova A: Slow internalization of anti-HER2 synthetic affibody monomer ${ }^{111}$ In-DOTA-ZHER2:342-pep2: implications for development of labeled tracers. Cancer Biother Radiopharm 23: 435-442, 2008.

37. Orlova A, Rosik D, Sandström M, Lundqvist H, Einarsson L and Tolmachev V: Evaluation of [111/114mIn]CHX-A"-DTPAZHER2:342, an Affibody ligand coniugate for targeting of HER2-expressing malignant tumors. Q J Nucl Med Mol Imaging 51: 314-323, 2007

38. Tolmachev V, Orlova A, Nilsson FY, Feldwich J, Wennborg A and Abrahmsén L: Affibody molecules: potential for in vivo imaging of molecular targets for cancer therapy. Expert Opin Biol Ther 7: 555-568, 2007

39. Baum RP, Prasad V, Müller D, et al: Molecular imaging of HER2-expressing malignant tumors in breast cancer patients using synthetic ${ }^{111} \mathrm{In}$ - or $68 \mathrm{Ga}$-labeled affibody molecules. J Nucl Med 51: 892-897, 2010. 